\title{
Structural and functional bases for broad-spectrum neutralization of avian and human influenza A viruses
}

\author{
Jianhua Sui ${ }^{1,4}$, William C Hwang ${ }^{2,4}$, Sandra Perez ${ }^{3}, \mathrm{Ge} \mathrm{Wei}^{2}$, Daniel Aird ${ }^{1}$, Li-mei Chen ${ }^{3}$, Eugenio Santelli ${ }^{2}$, \\ Boguslaw Stec ${ }^{2}$, Greg Cadwell ${ }^{2}$, Maryam Ali $^{1}$, Hongquan Wan $^{3}$, Akikazu Murakami ${ }^{1}$, Anuradha Yammanuru ${ }^{1}$, \\ Thomas Han ${ }^{1}$, Nancy J Cox ${ }^{3}$, Laurie A Bankston ${ }^{2}$, Ruben O Donis ${ }^{3}$, Robert C Liddington ${ }^{2}$ \\ \& Wayne A Marasco ${ }^{1}$
}

\begin{abstract}
Influenza virus remains a serious health threat, owing to its ability to evade immune surveillance through rapid genetic drift and reassortment. Here we used a human non-immune antibody phage-display library and the $\mathrm{H} 5$ hemagglutinin ectodomain to select ten neutralizing antibodies (nAbs) that were effective against all group 1 influenza viruses tested, including H5N1 'bird flu' and the H1N1 'Spanish flu'. The crystal structure of one such nAb bound to $\mathrm{H} 5$ shows that it blocks infection by inserting its heavy chain into a conserved pocket in the stem region, thus preventing membrane fusion. Nine of the nAbs employ the germline gene $V H 1-69$, and all seem to use the same neutralizing mechanism. Our data further suggest that this region is recalcitrant to neutralization escape and that nAb-based immunotherapy is a promising strategy for broad-spectrum protection against seasonal and pandemic influenza viruses.
\end{abstract}

Seasonal influenza A is a scourge of the young and old, killing more than 250,000 worldwide each year, while creating an economic burden for millions ${ }^{1}$. Pandemic influenza, which occurs when a new virus emerges and infects people globally that have little or no immunity, represents a grave threat to human health; for example, the 1918 Spanish Flu pandemic caused an estimated 50 million deaths ${ }^{2,3}$. Vaccines have historically been the mainstay of infection control. However, owing to rapid antigenic drift, the vaccine antigen must be updated annually based on global influenza surveillance ${ }^{4,5}$, and it is not always fully successful. In addition, some recent $\mathrm{H} 5 \mathrm{~N} 1$ vaccines have shown promising results ${ }^{6-9}$, but none has been reported to elicit a broad neutralizing response in humans. Neuraminidase inhibitors, especially oseltamavir (Tamiflu), remain the primary treatment, but they have limited efficacy if administered late in infection, and widespread use is likely to result in the emergence of resistant viral strains ${ }^{10,11}$.

Influenza $\mathrm{A}$ is subclassified by its two major surface proteins: hemagglutinin, which mediates cell entry, first by recognizing host proteins bearing sialic acid on their surface, and second by triggering the fusion of viral and host membranes following endocytosis, allowing viral RNA to enter the cytoplasm; and neuraminidase, which cleaves sialic acid from host and viral proteins, facilitating cell exit $^{12}$. There are 16 hemagglutinin subtypes (H1-16) and 9 neuraminidase subtypes (N1-9) that make up all known strains of influenza A viruses by various combinations of hemagglutinin and neuraminidase $^{12}$ (Supplementary Fig. 1 online).

The recent spread of highly pathogenic avian influenza (HPAI), caused by the H5N1 strain, across Asia, Europe and Africa raises the specter of a new pandemic, should the virus mutate to become readily transmissible from person to person. The evolution of $\mathrm{H} 5 \mathrm{~N} 1$ into a pandemic threat could occur through a single reassortment of its segmented genome or through the slower process of genetic drift ${ }^{12,13}$. Nearly 400 human H5N1 infections have been reported since 1997 from 14 countries, with a case mortality rate in the immunocompetent population above $60 \% 4$.

New therapeutic strategies that provide potent and broadly crossprotective host immunity are therefore a global public health priority. Human mAb-based 'passive' immunotherapy is now being used to treat numerous human diseases, including respiratory syncytial virus infection, and we have proposed how immunotherapy could be used strategically in a viral outbreak setting ${ }^{14}$.

In the present study, we first used a phage-display antibody library and recombinant $\mathrm{H} 5$ trimeric ectodomain to isolate a group of highaffinity nAbs that were potent inhibitors of $\mathrm{H} 5 \mathrm{~N} 1$ viral infection in vitro and in vivo. On the basis of crystallographic and functional studies, we showed that the nAbs bind to a common epitopea highly conserved pocket in the stem region of hemagglutinin containing the 'fusion peptide' - that rationalizes their ability to block

${ }^{1}$ Department of Cancer Immunology \& AIDS, Dana-Farber Cancer Institute; Department of Medicine, Harvard Medical School, 44 Binney Street JFB 826, Boston, Massachusetts 02115, USA. ${ }^{2}$ Infectious and Inflammatory Disease Center, Burnham Institute for Medical Research, 10901 North Torrey Pines Road, La Jolla, California 92037, USA. ${ }^{3}$ Influenza Division, Centers for Disease Control and Prevention, National Center for Immunization and Respiratory Diseases,

1600 Clifton Road, Mail Stop G-16, Atlanta, Georgia 30333, USA. ${ }^{4}$ These authors contributed equally to this work. Correspondence should be addressed to J.S. (jianhua_sui@dfci.harvard.edu), R.O.D. (rvd6@cdc.gov), R.C.L. (rlidding@burnham.org) or W.A.M. (wayne_marasco@dfci.harvard.edu). 
a
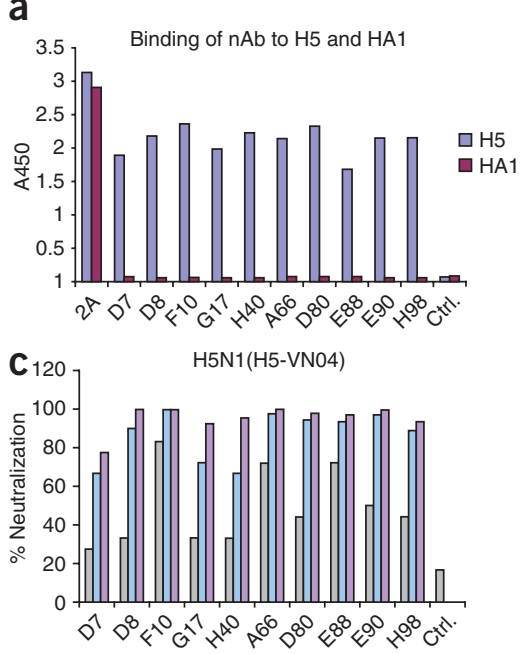

b
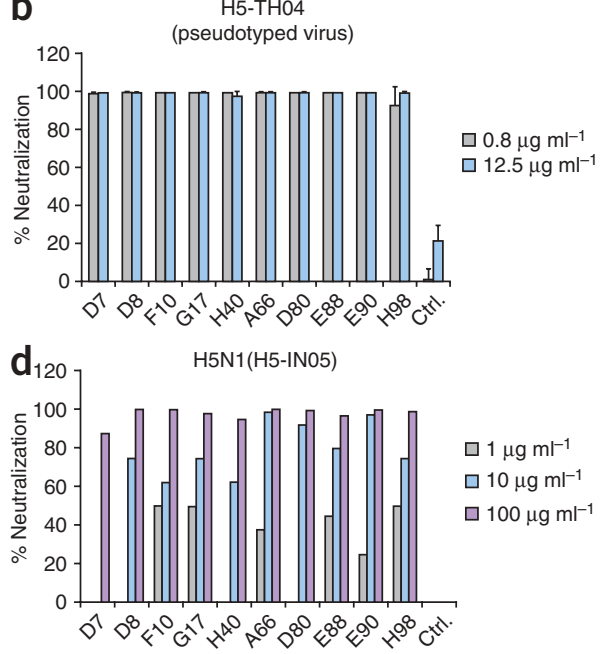

Figure 1 In vitro binding and neutralization of anti-H5 antibodies. (a) The ten antibodies were converted to soluble scFv-Fcs (scFv linked to the hinge, $\mathrm{CH} 2$ and $\mathrm{CH} 3$ domains of human IgG1) and evaluated for binding to trimeric $\mathrm{H} 5-\mathrm{THO} 4$ or monomeric $\mathrm{HA} 1$ of $\mathrm{H} 5-\mathrm{THO} 4$ coated on an ELISA plate. The $\mathrm{H} 5 \mathrm{scFv}$-Fcs recognize trimeric $\mathrm{H} 5$ but not HA1. An antibody raised against HA1 (2A) recognized both. (b) Neutralization of $\mathrm{H} 5-\mathrm{TH}$ 4-pseudotyped viruses (virus-like particles with HIV-1 only cores that display H5 on their surface). Percentage of neutralization at two concentrations is shown with s.d. The mAb $80 R^{18}$ was used as a negative control (Ctrl.). (c,d) Neutralization of wild-type H5-VNO4 and H5-INO5 by the ten ScFv-Fcs at three concentrations using a plaque reduction assay. Results are consistent with those obtained from a microneutralization assay (data not shown). membrane fusion rather than cell attachment. Sequence and structural analysis of all 16 hemagglutinin subtypes point to the existence of just two variants of this epitope, corresponding to the two classic phylogenetic groupings of hemagglutinin (groups 1 and 2). We therefore tested eight more group 1 hemagglutinin subtypes and demonstrated an unprecedented cross-subtype binding and/or neutralization spectrum. Because we had used a group 1 subtype (H5) for our panning, our nAbs, as expected, failed to neutralize group 2 subtypes $\mathrm{H} 3$ and H7. These results nevertheless raise the possibility that a cocktail comprising a small subset of nAbs raised against representatives of the two groups could provide broad protection against all seasonal and pandemic influenza A viruses.

\section{RESULTS}

\section{Identification of $\mathrm{nAbs}$ against $\mathrm{H} 5 \mathrm{~N} 1$}

The current $\mathrm{H} 5 \mathrm{~N} 1$ epidemics involve viruses derived from a single lineage of $\mathrm{H} 5$ hemagglutinin. Within this lineage, four distinct clades have been identified as major threats to public health ${ }^{15,16}$. We expressed recombinant trimeric ectodomain of $\mathrm{H} 5$ hemagglutinin from one of these viruses (strain A/Vietnam/1203/04 (H5N1), 'H5-VN04', clade 1) in insect cells ${ }^{17}$ (Supplementary Fig. 2 online), immobilized it on a plastic surface and selected antibodies from a 'non-immune' human antibody phage-display library (using single-chain VH-VL fragments ('scFv')) ${ }^{18}$. Two rounds of panning and the screening of 392 clones identified 10 unique antibodies formed by six distinct $\mathrm{VH}$ (variable region of heavy chain) fragments in combination with ten different VL (variable region of light chain) fragments (Supplementary Table 1 online).

We found that all ten nAbs bound trimeric H5-VN04 with similar avidity, but did not bind monomeric HA1 (Fig. 1a). Presented as scFv-Fc constructs, they potently neutralized the clade $1 \mathrm{H} 5$ pseudovirus, A/Thailand/2-SP-33/2004 (H5N1) ('H5-TH04') (Fig. 1b); and, in a stringent plaque-reduction assay, they all showed high levels of neutralization against $\mathrm{H} 5-\mathrm{VN} 04$, as well as the more divergent (clade 2.1) A/Indonesia/5/2005 ('H5-IN05') (Fig. 1c,d). We further found that the nAbs cross-competed with each other in a competition enzyme-linked immunosorbent assay (ELISA; Supplementary Fig. 3 online), suggesting that they share a common epitope. On the basis of this finding, as well as $\mathrm{VH}$ sequence diversity and neutralization potency, we converted three of the nAbs (D8, F10 and A66) into full-length human IgG1s for further studies; all three IgG1s bound to recombinant H5-VN04 with high affinity $\left(K_{\mathrm{d}} \sim 100-200 \mathrm{pM}\right)$ and slow dissociation rates $\left(k_{\mathrm{d}} \sim 10^{-4} \mathrm{~s}^{-1}\right)$ (Supplementary Fig. 4 online).

\section{Prophylactic and therapeutic efficacy in mice}

We evaluated the protective efficacy of the three IgG1s against $\mathrm{H} 5 \mathrm{~N} 1$ virus infection in a BALB/c mouse model (Fig. 2). Mice were treated with IgG1s before (prophylactically) or after (therapeutically) lethal viral challenge. Prophylaxis using $10 \mathrm{mg} \mathrm{kg}^{-1}$ of IgG1s effectively protected $(80-100 \%)$ mice when challenged with a high lethal dose of H5-VN04 (clade 1) or A/HongKong/483/97 ('H5-HK97') (clade 0) (Fig. 2a,b). Therapeutic treatment with $15 \mathrm{mg} \mathrm{kg}^{-1}$ (an achievable dose in humans) of IgG1 $24 \mathrm{~h}$ post-inoculation (hpi) also protected $80-100 \%$ of the mice challenged with either H5-VN04 or H5-HK97 virus (Fig. 2c,d). Mice treated at later times ( 48 hpi or $72 \mathrm{hpi}$ ) with H5-VN04 showed similar or higher levels of protection (Fig. 2e,f). Furthermore, surviving mice remained healthy and showed minimal body weight loss over the 2-week observation period (data not shown).

Whereas human influenza viruses are typically restricted to the upper respiratory tract, systemic spread is a typical outcome of $\mathrm{H} 5 \mathrm{~N} 1$ infection in mice, and it has been reported in some humans. We found that the three IgG1s caused potent suppression of viral replication in the lungs (measured $4 \mathrm{~d}$ after viral challenge) of mice treated within $48 \mathrm{~h}$ of viral challenge; and that two IgG1s, F10 and A66, were effective when given at 72 hpi. The strong impact of antibody therapy on systemic infection was demonstrated by $\geq 1,000$-fold suppression of virus spread to the spleen, even when given 72 hpi (Supplementary Fig. 5 online). We also observed suppression in the brain, but in this case, systemic spread was too low in control animals for accurate quantitation.

\section{nAbs inhibit cell fusion rather than receptor binding}

Two ways in which anti-hemagglutinin antibodies can neutralize infection is by blocking the initial binding of hemagglutinin to its cellular receptor (sialic acid) or by interfering with the subsequent step of hemagglutinin-mediated virus-host membrane fusion, which occurs in acidic endosomes ${ }^{19,20}$. We found that none of the nAbs inhibited virus binding to cells (Fig. 3a) or hemagglutination of red blood cells (data not shown). However, we were able to show, using a model system of cell fusion, that the nAbs potently inhibited membrane fusion (Fig. 3b). 

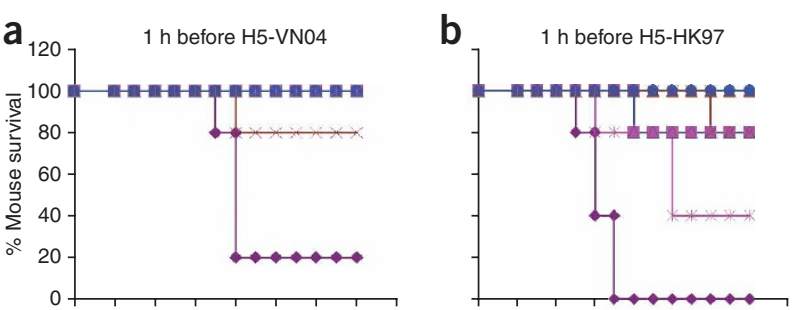

$-\mathrm{F} 10\left(10 \mathrm{mg} \mathrm{kg}^{-1}\right)$

$\leftarrow$ F10 $\left(2.5 \mathrm{mg} \mathrm{kg}^{-1}\right)$

- A66 (10 mg kg-1)

$-\triangle \mathrm{A} 66\left(2.5 \mathrm{mg} \mathrm{kg}^{-1}\right)$

- D8 $\left(10 \mathrm{mg} \mathrm{kg}^{-1}\right)$

* D8 $\left(2.5 \mathrm{mg} \mathrm{kg}^{-1}\right)$

Ctrl.80R (15 mg kg-1)
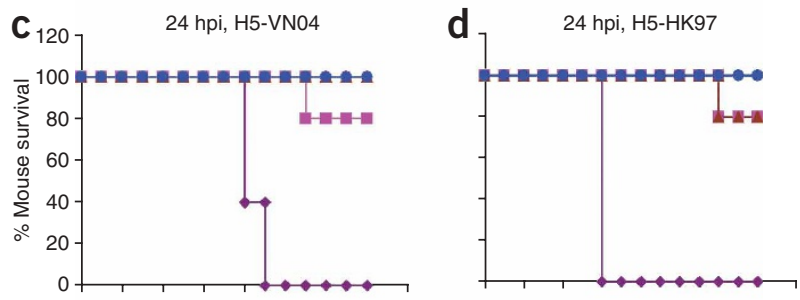

$-\mathrm{F} 10\left(15 \mathrm{mg} \mathrm{kg}^{-1}\right)$

- A66 (15 mg kg ${ }^{-1}$ )

D8 (15 mg kg-1)

$-\operatorname{Ctrl} .80 \mathrm{R}\left(15 \mathrm{mg} \mathrm{kg}^{-1}\right)$
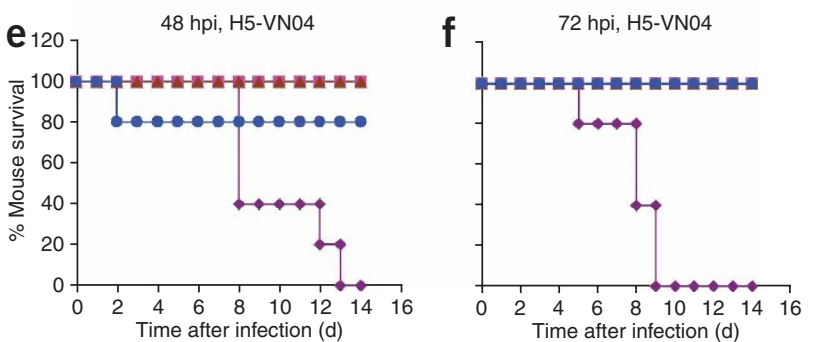

$-\mathrm{F} 10\left(15 \mathrm{mg} \mathrm{kg}^{-1}\right)$

- A66 (15 mg kg-1)

Figure 2 Prophylactic and therapeutic efficacy of anti-H5 nAbs in mice. (a,b) Prophylactic efficacy Percentage of survival of mice treated with anti-H5 nAbs or control mAb $1 \mathrm{~h}$ before lethal challenge by intranasal inoculation with H5-VNO4 (a) or H5-HK97 (b) viruses. (c-f). Therapeutic efficacy. Mice were inoculated with H5-VNO4 and injected with nAbs at 24 h, 48 h of 72 hpi $(\mathbf{c}, \mathbf{e}, \mathbf{f})$ or with H5-HK97 at 24 hpi (d).

\section{Structural characterization of the nAb epitope}

To provide a structural basis for neutralization and to explore the prospects for developing even broader-spectrum therapeutics, we determined the crystal structure of F10 (as the scFv fragment) in complex with the H5 (H5-VN04) ectodomain (Fig. 4 and Supplementary Table 2 online). We used $\mathrm{H} 5$ activated by cleavage of the single-chain precursor, HA0, into two polypeptides, HA1 and HA2. Cleavage leads to the partial burial of the fusion peptide (the first $\sim 21$ residues of each HA2) into the stem ${ }^{19,21}$, which also contributes to the formation of each of three hydrophobic 'pockets' located below the large trimeric receptor binding head. In the complex, one F10 nAb binds into each pocket, burying $\sim 1,500 \AA^{2}$ of protein surface. Only the heavy chain $(\mathrm{VH})$ participates directly in binding, using all three of its complementarity-determining regions (CDRs). The light chain (VL) points out into solution and makes only nonspecific contacts with the distal end of the oligosaccharide of glycosylated residue Asn $33_{1}$ from a neighboring monomer. The epitope on $\mathrm{H} 5$ encompasses the entire pocket, which is formed by the HA2 fusion peptide flanked by elements of HA1 on one side and helix $\alpha$ A of HA2 on the other.

The key interactions are as follows (Fig. 4b). (i) CDR-H2 adopts the 'type 2' conformation ${ }^{22}$. Two hydrophobic residues, Met54 and Phe55, from the tip of $\mathrm{H} 2$ insert into the pocket. Phe55 lies across a flat hydrophobic surface formed by the main chain of the fusion peptide, residues $18_{2}-21_{2}$; it also makes favorable orthogonal aromatic interactions ${ }^{23}$ with the side chains of $\operatorname{Trp} 21_{2}$ at the back of the pocket and His $18_{1}$ at the front (subscripts 1 or 2 refer to HA1 or HA2, and the numbering scheme follows the structure of $\mathrm{H} 3$ (PDB $2 \mathrm{HMG})^{17,24}$ ).
D8 (15 mg kg-1)

Ctrl.80R (15 mg kg-1)

The Met54 sulfur makes $\Pi$-aromatic interactions $^{25}$ with the $\operatorname{Trp} 21_{2}$ ring, hydrophobic interactions with Ile $45_{2}$ from helix $\alpha \mathrm{A}$ and a hydrogen bond between Met54 $\mathrm{C}=\mathrm{O}$ and the His $38_{1}$ side chain. (ii) Tyr 102 from CDR-H3 extends from the apex of the $\mathrm{H} 3$ loop to a location only $\sim 3 \AA$ from Phe55, and it complements CDR-H2 by cementing together the fusion peptide (via a main chain hydrogen bond to Asp $19_{2}$ ) and the $\alpha$ A helix of HA2 (by intercalating between $\mathrm{Thr} 41_{2}$ and Ile $45_{2}$ ). A large hydrophobic residue at the neighboring position 103 supports the side chain conformation of Tyr102. (iii) The CDR-H1 loop is characterized by small hydrophobic or polar side chains (notably Val27, Thr28 and Ser31) such that CDR-H1 fits snugly beneath the hemagglutinin head while packing against helix $\alpha$ A. A somatic mutation of conserved Gly26, G26E, generates a noncanonical conformation for $\mathrm{H} 1$, with $\mathrm{Thr} 27$ pointing outward and making contact H5.

An N-terminal hairpin (residues Ile29 2 and $\mathrm{Met}^{3} \mathrm{O}_{2}$ ) from HA2 of the counterclockwise neighbor packs against the other side of helix $\alpha \mathrm{A}$ at this point, wrapping around its fusion peptide and further locking it into place (Fig. 4a,c). Thus, the F10 nAb may stabilize the fusion peptide of more than one subunit. One framework (FR3) residue, Gln74, seems to be especially important in stabilizing the CDR-H1 and CDR-H2 loop conformations, by forming hydrogen bonds to the main chain $\mathrm{C}=\mathrm{O}$ groups of Pro53 and Met54, as well as the side chain of Ser30. The FR3 residue at position 72 is the major determinant of the choice between two distinct conformations of the $\mathrm{H} 2$ loop $^{22}$.

Consistent with the structural data, mutations in three $\mathrm{H} 5$ residues on HA2 $\alpha$ A, Val52,$A s n 53_{2}$ and Ile56, which make important interactions with $\mathrm{F} 10$, greatly reduce or ablate $\mathrm{nAb}$ binding, whereas the conservative mutation V52L has no effect (Fig. 4c,d). Mutations to other surfaces of the $\alpha$ A helix either have no effect (typically exposed residues) or lead to increased $\mathrm{nAb}$ binding, perhaps by subtly increasing the flexibility of the epitope (Fig. 4d). Notably, the nine other nAbs show similar mutant binding profiles. Together with the cross-competition noted above, this strongly suggests that the epitopes for all ten nAbs overlap very closely indeed, and that the nAbs bind in a similar location and orientation.

\section{Structural basis of $\mathbf{H} 5$ neutralization by the $\mathbf{n A b}$ panel}

The broad neutralizing behavior against $\mathrm{H} 5$ may be attributed in part to the exclusive role of $\mathrm{VH}$ in antigen binding and the use of a common germline gene, $\mathrm{VH1}-69$, in five out of the six VHs, although their CDR3 loops are variable in sequence and length (13-17 residues) (Supplementary Fig. 6 and Supplementary Table 1 online). In addition, free-energy calculation ${ }^{26}$ point to dominant binding contributions ( $\sim 70 \%$ of the total favorable free energy) of the three conserved residues in the VH segment (Fig. 4b). In CDR-H2 derived from germline VH1-69, position 55 is always phenylalanine, and position 54 is always hydrophobic (methionine, isoleucine, leucine or valine). In our nAbs, CDR-H3 always has a tyrosine predicted to lie at the tip of the CDR3 loop (conserved at the position 6). The 

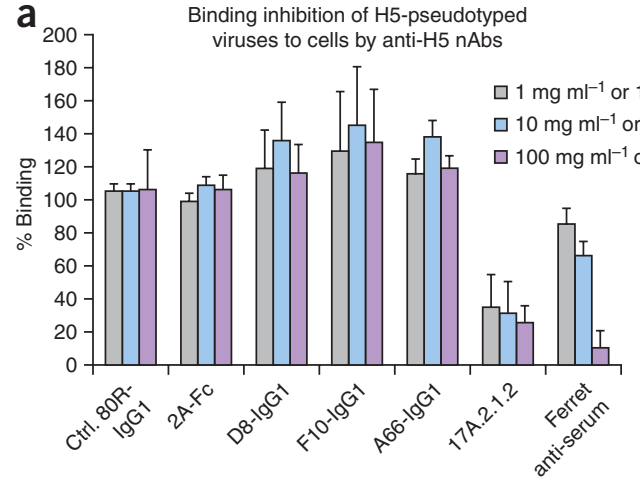

b

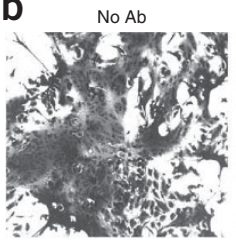

D8-IgG1
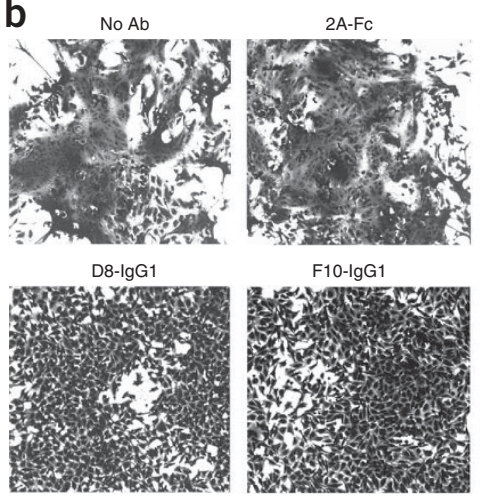

F10-lgG1

Ctrl. 80R-IgG1

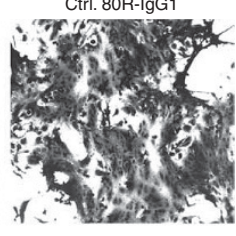

A66-IgG1
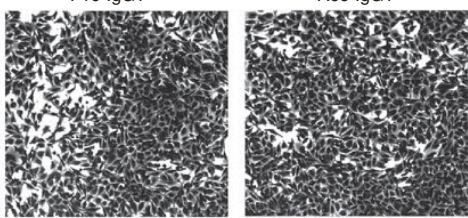

conformation and sequence of the CDR1 loop does not seem to be critical, because the other antibodies we isolated do not contain the somatic mutation (G26E) found in F10 and are predicted to have canonical structures. The sixth $\mathrm{VH}$ gene we isolated is derived from the germline gene VH1-2; its $\mathrm{H} 2$ loop has the same length as VH1-69, but by virtue of a change from alanine to arginine at position 72 (ref. 22) it is predicted to adopt a distinct conformation ('type 3') that presents loop residues 3 and 4 to the antigen (rather than residues 4 and 5 in type 2 loops). The specific somatic mutation at position 4 ,
Figure 3 Neutralization mechanism. (a) nAbs do not inhibit cell binding of full-length hemagglutinin from H5-TH04-pseudotyped HIV-1 viruses. None of the three nAb-treated viruses inhibited cell binding. Mouse anti-H5 mAb, 17A2.1.2 and ferret anti-H5N1 serum, which inhibit hemagglutination, were used as positive controls. Anti-SARS spike protein (8OR) and anti-HA1 (2A) were used as negative controls. Error bars represent s.d. (b) All three nAbs inhibit cell fusion. HeLa cells were transfected with H5-TH04-expressing plasmid and exposed to a pH 5.0 buffer for $4 \mathrm{~min}$ in the presence or absence of nAbs. Syncytia formation induced by the brief exposure to $\mathrm{pH} 5.0$ was completely inhibited by D8, F10 and A66, at $20 \mu \mathrm{g} \mathrm{ml}^{-1}$ $(\sim 0.13 \mu \mathrm{M})$, whereas controls (80R and anti-HA1 mAb (2A) at the same concentration had no effect.

from asparagine to methionine, presumably promotes $\mathrm{H} 5$ binding. It is not possible to predict the structure of the larger H3 loop, but a tyrosine located at the center of the loop may play an analogous role to that in F10.

Thus, the F10-H5 crystal structure suggests a common mechanism of $\mathrm{H} 5$ virus neutralization for our $\mathrm{nAb}$ panel. They make no contact with the receptor binding sites in the head and so do not inhibit cell attachment. Rather, they lock the fusion peptide and helix $\alpha \mathrm{A}$ in place, thereby preventing the large structural reorganizations that are required for membrane fusion ${ }^{17,19,27-30}$. Our data point to this event occurring at an early step in infection, although we cannot rule out the possibility that the nAbs act at a later stage, given the close packing of molecules on the surface of the mature virion, which might restrict early access to the epitope. The only previously published crystal structure of a hemagglutinin-nAb complex that inhibits membrane fusion uses a different mechanism: it prevents conformational changes by cross-linking the upper surfaces of adjacent subunits in the head ${ }^{31}$.

\section{NAbs bind and neutralize a broad range of group 1 viruses}

Next we examined all of the available hemagglutinin sequences (total 6,360 ) in the public influenza sequence database (Supplementary Table 3 online). Of note, the sequences of the F10 epitope are nearly always conserved within the H5 subtype. Indeed, many epitope residues, especially in HA2, are highly conserved across all 16 hemagglutinin subtypes (Fig. 5). This high sequence conservation
Figure 4 Structure of the H5-F10 complex. (a) Structure of the $\mathrm{H} 5$ trimer bound to $\mathrm{F} 10$ (scFv). $\mathrm{H} 5$ is similar to the uncomplexed structure $^{35}$ (pairwise r.m.s. deviation $(C \alpha)=1.0$ and $0.63 \AA$ for two independent trimers). HA1, $H A 2$, the $\alpha A$ helix of $H A 2$, the fusion peptide (FP) and F10 (VH and VL) are color coded. The third F10 molecule is hidden behind the stem. (b) Close-up of the epitope showing $\mathrm{H} 5$ as a molecular surface, with selected epitope residues labeled. The fusion peptide is in green. The tip of F10 (red ribbon) and selected CDR side chains are shown. Of $1,500 \AA^{2}$ buried surface at the interface, $43 \%$ involves hydrophobic interactions. (c) Surface of the central stem region, showing two $\mathrm{H} 5$ monomers. One monomer has HA1 (yellow) and HA2 (blue) colored differently; the path of the FP through the epitope (red) is outlined, and mutations that do not affect binding are colored cyan (Fig. 4d). The fusion peptides (FP and $F P^{\prime}$ ) are labeled in both

monomers. Epitope residues are labeled white (HA2) or yellow (HA1), and the position of buried residue $\mathrm{H}_{11} 11_{2}$ is shown as a black ball labeled ' $\mathrm{H}$ '. (d) Binding of the three nAbs to H5 mutants in the $\alpha \mathrm{A}$ helix, transiently transfected into 293T cells. Note the similar response to all mutants tested. Mutations were made either to alanine or to the corresponding $\mathrm{H} 7$ residue; $24 \mathrm{~h}$ after transfection, $\mathrm{nAbs}$ or ferret anti-H5N1 serum was used to stain the transfected cells. Fluorescent intensity was normalized against ferret anti-serum (100\%) to account for different expression levels. a

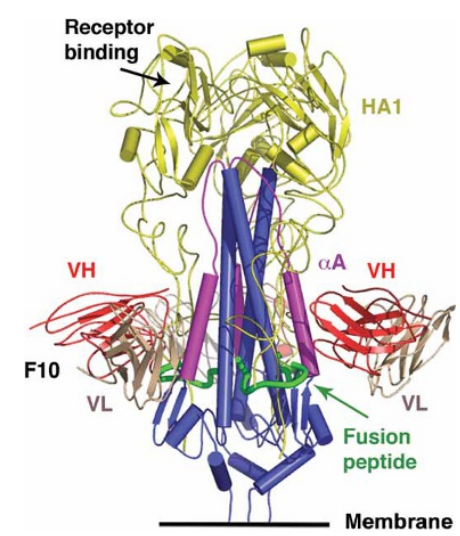

b

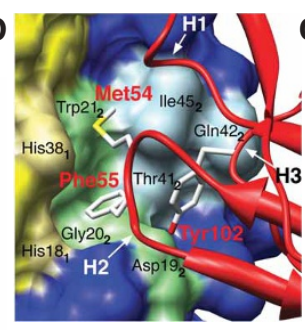

d

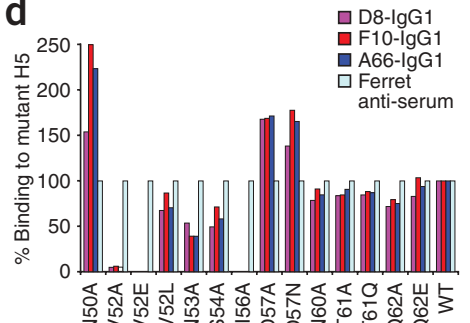

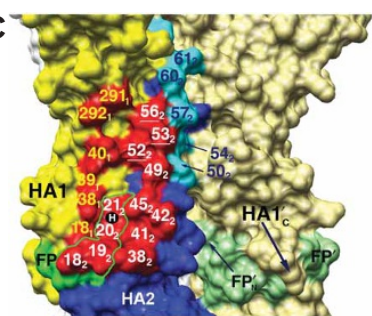

D8- $\lg G 1$ F10-IgG1 Ferret A6ret

(1) 


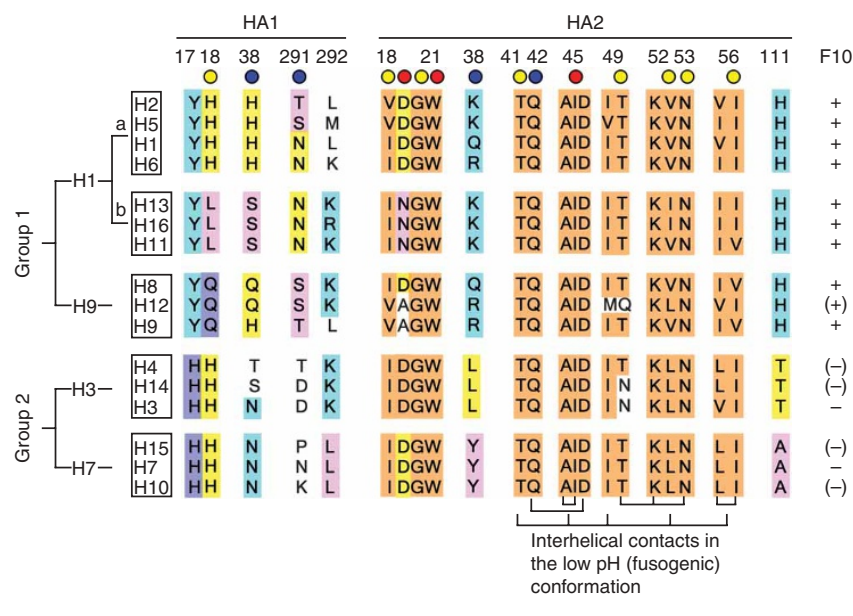

provides a rationale for the cross-neutralization of the $\mathrm{H} 5 \mathrm{~N} 1$ virus clades described above, and this prompted us to test our antibodies against a broader range of hemagglutinin subtypes.

Group 1 viruses, which contain 10 of the 16 subtypes, are further classified into three 'clusters': H1a, H1b and H9 (refs. 32,33; Fig. 5). We tested $\mathrm{nAb}$ binding to eight members of clusters H1a, H1b and $\mathrm{H} 9$, which include avian $\mathrm{H} 5$ and the most common human influenza subtypes (the major exception is the group 2 subtype, H3). In addition to $\mathrm{H} 5$, we found that all three IgG1s bound to cells expressing full-length $\mathrm{H} 1$ from three different strains of H1N1, including the 1918 Spanish flu, H2 from H2N2 and H6 from H6N2, the Cluster 1b subtypes H11 from H11N9, H13 from $\mathrm{H} 13 \mathrm{~N} 6$ and $\mathrm{H} 16$ from $\mathrm{H} 16 \mathrm{~N} 3$, and the

Figure 6 Cross-subtype neutralization by nAbs. (a) nAbs D8, F10 and A66 all neutralized indicated pseudotyped viruses (strains described below). Error bars indicate s.d. (b) Microneutralization assay. Neutralization titers (0.1 $\mathrm{mg} \mathrm{ml}^{-1}$ antibody stock solution) of $\mathrm{nAb}$ F10 against wild-type H5N1, H1N1, H2N2, H6N1, H6N2, H8N4, H9N2 and H3N2 virus strains. $80 \mathrm{R}$ is the negative control. Vertical bars and whiskers represent the lowest and the highest neutralization titer ( $2 \chi$, values of $\chi$ are shown on the $y$ axis), respectively, of two or three independent experiments. (c,d) Prophylactic efficacy against two H1N1 strains in mice. Percentage of survival of mice treated with anti-H5 nAbs or control mAb are shown before lethal challenge by intranasal inoculation with H1-WSN33 (c) or H1-PR34 (d) viruses. Complete viral strain designations are: $\mathrm{H} 1-\mathrm{OH} 83$ (A/Ohio/ 83 (H1N1)); H1-PR34 (A/Puerto Rico/8/34 (H1N1)); H1-SC1918 (A/South Carolina/1/1918 (H1N1)); H1-WSN33 (A/WSN/1933 (H1N1)); H2-AA60 (A/Ann Arbor/6/60 (H2N2)); H2-JP57 (A/Japan/305/57(H2N2)); H3-SY97 (A/Sydney/5/ 97(H3N2)); H6-HK99 (A/quail/Hong Kong/172130/99(H6N1)); H6-NY98 (A/chicken/New York/ 14677-13/1998 (H6N2)); H7-FP34 (A/FPV/ Rostock/34 (H7N1)); H8-ON68 (A/turkey/Ontario/ 6118/68); H9-HK(G9)97 (A/chicken/HongKong/ G9/97 (H9N2)); H9-HK99 (A/HongKong/1073/ 99 (H9N2)); H11-MP74 (A/duck/Memphis/546/ 74 (H11N9)).
Figure 5 Sequence conservation in hemagglutinin groups, clusters and subtypes at the F10 epitope. Circles below residue numbers indicate estimated contribution to the binding energy at each position: red, strong; yellow, intermediate; blue, neutral. Residues without a circle are not directly involved in the epitope but are discussed in the text. Colored highlighting on the sequences indicates conservation within clusters and groups, with orange indicating high conservation or invariance. Other colors (for example, yellow, cyan and pink) highlight residues that are cluster or subtype specific. The network of interhelical contacts that stabilize the fusogenic structure ${ }^{61}$ are indicated below the HA2 sequences. Subtypes that can be recognized/ neutralized by F10 are indicated with ' + ' on the far right. (+) or (-) indicates a predicted positive or negative binding, respectively.

Cluster H9 subtypes from three H9N2 strains. However, none of them bound to a group 2 subtype, H7 from H7N1 (Supplementary Fig. 7 online).

The IgG1s also neutralized H5-, H1-, H2-, H6- and H11-pseudotyped virus infections (Fig. 6a). In a microneutralization assay, F10-IgG1 also neutralized H5N1, H1N1, H2N2, H6N1, H6N2, H8N4 and H9N2 influenza viruses (Fig. 6b). However, none of the nAbs neutralized group 2 viruses, for example, H3N2 (Fig. $6 \mathbf{b}$ and Supplementary Fig. 8 online). Thus, these nAbs recognize an epitope on hemagglutinin that is conserved among $\mathrm{H} 5$ clades and in all members of group 1 viruses. Finally, we demonstrated the in vivo protective efficacy of two of the IgG1s against two lethal H1N1 viral strains in a BALB/c mouse model, using the same protocol as for the H5N1 studies (Fig. 6c,d).
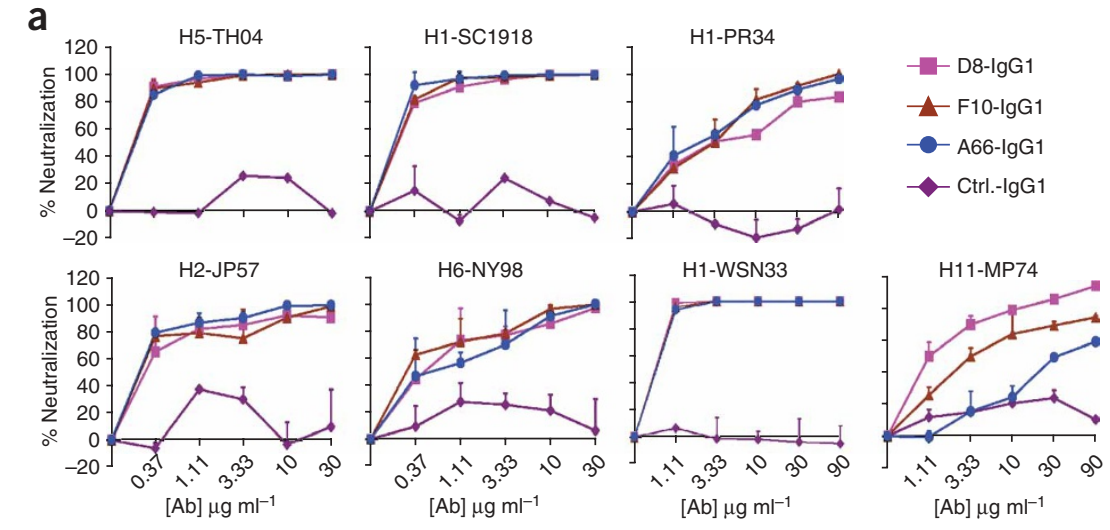

b
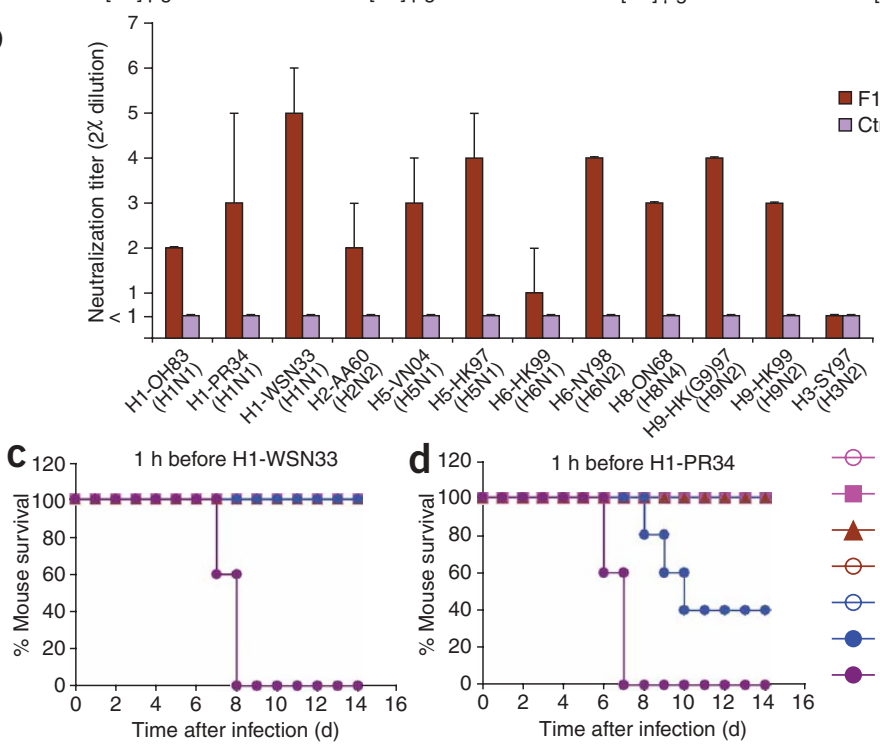

$-\mathrm{D} 825 \mathrm{mg} \mathrm{kg}^{-1}$
$-\mathrm{D} 810 \mathrm{mg} \mathrm{kg}^{-1}$
$-\mathrm{F} 1010 \mathrm{mg} \mathrm{kg}^{-1}$
$-\mathrm{F} 1025 \mathrm{mg} \mathrm{kg}^{-1}$
$-\mathrm{A} 6625 \mathrm{mg} \mathrm{kg}^{-1}$
$-\mathrm{A} 610 \mathrm{mg} \mathrm{kg}^{-1}$
$-80 \mathrm{R} 25 \mathrm{mg} \mathrm{kg}^{-1}$ 

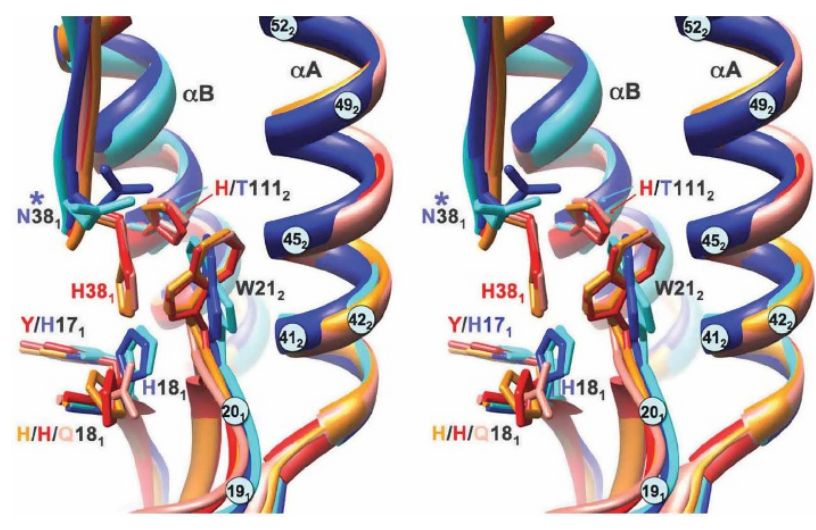

Basis of the group-specific broad-spectrum virus neutralization The ability of our nAbs to recognize all group 1 (cluster $\mathrm{H} 1 \mathrm{a} / \mathrm{b}$ and $\mathrm{H} 9$ ) viruses (H12 was not tested) can be attributed to the key conserved features of the nAbs described above in combination with the highly conserved pocket on hemagglutinin (Figs. 4 and 5). The epitope may be divided into three elements. (i) At its center, the sequence of the $\mathrm{N}$-terminal segment of HA2-fusion peptide residues $18_{2}-21_{2}$-is conserved across all hemagglutinin subtypes (note that the side chain at position $19_{2}$ does not participate in binding). (ii) A downstream segment of HA2 adopts part of the $\alpha \mathrm{A}$ helix (residues $39_{2}-56_{2}$ ), which is nearly invariant; the only significant difference is a threonine to glutamine change at position $49_{2}$ in the untested $\mathrm{H} 9$ cluster subtype, H12. Thr $49_{2}$ lies at the periphery of the epitope and makes one long hydrogen bond $(3.5 \AA)$ to Ser31. Simple modeling suggests that there is plenty of space to accommodate the larger glutamine side chain and that it can make comparable hydrogen bonds. (iii) Smaller contributions from segments of the HAl chain (residues $18_{1}$ and $38_{1}$ ) and a loop at the base of the head (residues $291_{1}$ and $292_{1}$ ).

Three-dimensional comparisons of the epitope in the five known crystal structure subtypes (three from group 1 ( $\mathrm{H} 1, \mathrm{H} 5$ and $\mathrm{H} 9)$ and two from group $\left.2(\mathrm{H} 3 \text { and } \mathrm{H} 7)^{21,32,34-36}\right)$ show that they adopt two distinct structural classes consistent with the phylogenetic groupings $^{32,33}$ (Fig. 7). These differences arise from group-specific differences in the location of buried residues, notably histidines $\left(\mathrm{H}_{111_{2}}\right.$ is unique to group $1 ; \mathrm{H}_{1} 7_{1}$ is unique to group 2) that have been proposed to be the 'triggers' for $\mathrm{pH}$-induced conformational changes ${ }^{29}$. The differences cause the side chain of $\operatorname{Trp} 21_{2}$ to turn through $90^{\circ}$ in group 2 subtypes, eliminating favorable binding to Phe55 from our $\mathrm{nAb}$ panel. In addition, four out of six group 2 subtypes are glycosylated at position $38_{1}$, at the periphery of the F10 epitope; our modeling studies predict steric clashes with the CDR-H1 loop (data not shown). These structural differences rationalize the observed lack of binding and neutralization of group 2 hemagglutinin subtypes and viruses.

\section{Prospects for immune escape}

The remarkable transformation to the fusogenic state includes repacking of the central helices of three HA2 protomers to form a new triplehelical bundle, in which residues 34-37 form an N-terminal cap, and the creation of C-terminal arms that extend to the $\mathrm{N}$ terminus of the new bundle ${ }^{37}$. It is straightforward to model the locations of the F10 epitope residues in this model of the fusogenic state (Supplementary Note 1 online). All eight epitope residues, which were fully exposed in the neutral $\mathrm{pH}$ structure, become either part of the new hydrophobic bundle core ( $\mathrm{Thr} 41_{2}, \mathrm{Ile} 45_{2}, \mathrm{Val} 52_{2}$ and Ile56 2 ) or they make networks
Figure 7 Three-dimensional comparison of the F10 epitope in group 1 and group 2 hemagglutinins. Stereo overlay of crystal structures of the five known hemagglutinin subtypes in the region of the F10 epitope, showing conservation and differences between the two phylogenetic groups. $\mathrm{H} 1, \mathrm{H} 5$ and $\mathrm{H} 9$ (group 1) are in shades of red and yellow (PDB 1RU7, 2IBX and 1JSD); $\mathrm{H} 3$ and $\mathrm{H} 7$ (group 2) are in shades of blue (PDB $1 \mathrm{MQL}$ and $1 \mathrm{TI}$ ). R.m.s. differences for pairwise overlays are $0.56 \pm 0.11 \AA$ (observed range group 1), $0.75 \AA$ (group 2) and $1.21 \pm 0.12 \AA$ between groups. Consistent differences between phylogenetic groups include the orientation of Trp2 $1_{2}$ and alternative side chain directions at $18_{1}$ and $38_{1}$, which are linked to the packing of buried $\mathrm{His} 11_{2}$ (the putative $\mathrm{pH}$ trigger in group 1 ; absent in group 2), and the burial of the larger tyrosine (group 1) versus histidine (the putative $\mathrm{pH}$ trigger in group 2) at $17_{1}$. Of particular note, Asn38 1 is glycosylated in four members of the group 2 clusters. Other epitope residues are indicated by numbered light blue circles. of hydrogen bonds with the C-terminal arms and other elements that stabilize the new bundle (Lys $38_{2}, \mathrm{Gln} 42_{2}, \mathrm{Thr} 49_{2}$ and $A s n 53_{2}$ ). The requirement for adopting two entirely different conformations, each with a distinct hydrophobic core and hydrogen-bonding network may place powerful evolutionary constraints on the sequence of the helix, as evidenced by the almost complete lack of genetic drift within helix $\alpha \mathrm{A}$ among the 16 hemagglutinin subtypes.

To test this hypothesis, we attempted to select neutralization-escape mutants. We propagated VN/04 (H5N1) virus in MDCK cells for $72 \mathrm{~h}$ in the presence of $40 \mu \mathrm{g} \mathrm{ml}^{-1}$ of each of the $3 \mathrm{nAbs}$ as well as a murine antibody, 22F, that targets the receptor binding head. Following three in vitro passages, we readily isolated a mutant VN04 virus (K193E) that was resistant to $22 \mathrm{~F}$. In contrast, we failed to identify any viruses resistant to any of our three IgG1s (D8, F10 or A66). Although these experiments cannot prove that escape mutants with unimpaired viral fitness will never arise, they clearly support the notion that the pocket is more refractory than epitopes in the head. Notwithstanding, if such mutants should arise, we can use our in vitro approach to find new reactive nAbs, or further engineer the existing $\mathrm{nAbs}$ to have even broader spectrum reactivity ${ }^{38}$.

\section{DISCUSSION}

Before the present study, the vast majority of nAbs isolated against influenza A virus have targeted the receptor binding head and lacked broad cross-neutralizing activity. However, a murine nAb, termed C179 (ref. 39), was positively selected on the basis of its cross-neutralization properties (of $\mathrm{H} 1$ and $\mathrm{H} 2$ subtypes) and was subsequently shown to neutralize $\mathrm{H} 5$, but not group 2 , subtypes ${ }^{39,40}$ (Supplementary Note 2 online). Moreover, C179 was shown to block membrane fusion rather than cell attachment and to protect mice against viral challenge ${ }^{41}$, although a detailed mechanism was not reported. We compared the activities of C179 and F10 and found that both showed similar binding toward H5. We also found that F10 efficiently competed with $\mathrm{C} 179$ for binding to $\mathrm{H} 5$, but not vice versa (Supplementary Fig. 9 online). Furthermore, the point mutant $\mathrm{V} 52_{2} \mathrm{E}$ abrogated binding to both antibodies, whereas $\mathrm{T} 318_{1} \mathrm{~K}$ affected only C179 binding. These results suggest that F10 and C179 have partially overlapping epitopes and that their modes of action are similar.

The manner in which hemagglutinin was presented to the antibody phage-display library in this study seems to have been crucial in our success, because similar attempts to isolate broadly nAbs using cellsurface expressed hemagglutinin showed only partial success against $\mathrm{H} 5$, and most antibodies recognized linear epitopes ${ }^{42}$. As noted above, we repeatedly isolated nAbs that use the same $\mathrm{VH}$ germline gene (IGHV1-69 or ' $V H 1-69$ '). One published study pointed out that this is the only $\mathrm{VH}$ gene that consistently encodes two hydrophobic residues 
at the tip of its CDR-H2 loop ${ }^{43}$; indeed, it is the only germline gene to encode a phenylalanine at this position, which makes several crucial interactions with H5. Moreover, the 'type 2' H2 loop, which is long and compact, is predicted to occur in only 4 out of the $\sim 50$ human germline genes. These factors may explain at least in part the ability of nAbs derived from this germline gene to cross-react with viral epitopes through their unusual ability to bind to conserved hydrophobic pockets. Such pockets are likely to have an important function and for this reason they are often cryptic in the unactivated state of the antigen. For example, VH1-69 is the predominant gene used by a group of CD4-induced nAbs raised against the HIV-1 surface glycoprotein, gp120, where the pocket is part of a conserved co-receptor binding site that is exposed only transiently upon binding to its primary receptor, CD4 (ref. 43). Similarly, an antibody raised against the HIV gp41 trimeric 'inner-core' fusion protein intermediate uses the hydrophobic tip of its VH1-69 CDR-H2 loop to insert into a conserved hydrophobic pocket that blocks further assembly to the fusion-competent six-helix structure ${ }^{44}$. In vivo, B cells carrying the VH1-69 gene are the primary mediators of innate defense against $\mathrm{HCV}$ infection, generating antibodies against its membrane-fusion glycoprotein, E2 (ref. 45), although the epitope and mode of action have not been determined. Notably, as we found here, VH1-69 is not the only germline gene that is suitable for achieving neutralization in a similar manner. Another recent example is a nAb against the Ebola virus surface glycoprotein, KZ52, which uses the VH3-21 germline gene $^{46}$. However, their common ability to lock viral envelope proteins into a nonfusogenic conformation suggests a general strategy for broad-spectrum and/or potent viral neutralization.

Recent work using immune-based phage-display libraries generated from B cell populations of patients who survived H5N1 infection resulted in the isolation of three human nAbs that neutralized both $\mathrm{H} 1$ and $\mathrm{H} 5$ viral strains. The authors postulated that the reason for survival was an effective humoral immune response mediated by such nAb-generating B cells in vivo ${ }^{47}$, although no control populations were studied. Analysis of their data (Supplementary Note 3 online) indicates that the antibodies are also derived from the VH1-69 germline gene and share other key characteristics, including the methionine-phenylalanine pair in CDR-H2 and a tyrosine at the tip of CDR-H3. Thus it would seem, at least in this case, that our nonimmune (H5-naive) donor library approach generated antibodies with characteristics similar to those found using immunized donorbased phage-display libraries derived from H5N1 survivors.

Why broad-spectrum nAbs similar to those identified in our study are not similarly generated and expanded during successive rounds of influenza infection and repeated vaccination is not known (Supplementary Note 4 online), and this question warrants further investigation. It is unlikely that the F10 epitope provokes self-tolerance mechanism(s) via auto-antigen mimicry ${ }^{48}$ (Supplementary Note 5 online). Rather, we hypothesize that an immunodominant antibody response to the highly exposed globular head may overwhelm the antibody response to the F10 epitope, although it remains possible that other immune exclusion mechanism(s) may preclude natural antibody responses against it. It is not surprising that many viruses are highly adept at keeping their most crucial (and conserved) determinants of pathogenesis cryptic, in which case subunit-based vaccines, using properly presented fragments of F10 or F10-like epitopes, may offer distinct advantages over whole virus-based approaches to induce broad spectrum nAbs in vivo ${ }^{49,50}$.

In summary, we have used in vitro methodologies to isolate a family of high-affinity broad-spectrum human nAbs against hemagglutinin that show potent in vitro and in vivo efficacy against both highly pathogenic $\mathrm{H} 5 \mathrm{~N} 1$ and $\mathrm{H} 1 \mathrm{~N} 1$ viruses. We show that they inhibit the post-attachment fusion process by recognizing a highly conserved epitope within the stem region of hemagglutinin at a point where key elements of the conformational change are brought into close apposition. Our initial experiments suggest that this region is recalcitrant to the generation of escape mutants. The prospects for their use for passive immunotherapy would therefore seem to be excellent, either alone or in combination with small-molecule inhibitors (Supplementary Note 6 online). Finally, our structural work pinpoints the reasons why group 2 hemagglutinins do not bind the nAbs described here: despite surface sequence similarities, they form a structurally distinct group, but one that is also highly conserved and therefore may be amenable to a similar panning discovery approach.

Note added in proof: Throsby et al. ${ }^{51}$ recently identified human $n A b s$ that recognize a broad range of group 1 influenza A viruses with similar VH1-69 germline gene usage.

\section{METHODS}

Crystallization of the H5-F10 complex. We generated H5-F10 complexes by incubating the two purified components with an excess of F10 (Supplementary Methods online) and isolated them by Superdex 200 in Tris-buffered saline (TBS) buffer. Peak fractions were pooled and concentrated to $\sim 11 \mathrm{mg} \mathrm{ml}^{-1}$. We examined the integrity of the $\mathrm{H} 5$ trimer using gel filtration and SDS-PAGE. Crystals grew at $22^{\circ} \mathrm{C}$ by equilibrating equal volumes of protein and reservoir solution $(12.5 \%$ PEG $1 \mathrm{~K}(\mathrm{w} / \mathrm{v}), 25 \%$ ethylene glycol $(\mathrm{w} / \mathrm{v}), 100 \mathrm{mM}$ Tris, $\mathrm{pH} 8.5$ ) using the hanging drop vapor diffusion technique.

Data collection, structure determination and refinement. We collected diffraction data from crystals that were flash frozen at $100 \mathrm{~K}$ in the reservoir

Table 1 Data collection and refinement statistics for H5-F10

\begin{tabular}{lc}
\hline & Native H5-F10 \\
\hline Data collection & \\
Space group & $C 2$ \\
Cell dimensions & \\
$\quad a, b, c(\AA)$ & $205,119,339$ \\
$\alpha, \beta, \gamma\left({ }^{\circ}\right)$ & $90,99.6,90$ \\
Resolution $(\AA)$ & $3.2(3.28-3.20)^{*}$ \\
$R_{\text {merge }}$ & $0.13(0.81)$ \\
$I / \sigma I$ & $9.5(2.0)$ \\
Completeness $(\%)$ & $85(68)$ \\
Redundancy & $4.5(4.5)$ \\
& \\
Refinement & \\
Resolution $(\AA)$ & \\
No. reflections & $50-3.2(3.28-3.20)$ \\
$R_{\text {work }} / R_{\text {free }}$ & 106,885 \\
No. atoms & $0.23(0.32) / 0.29(0.38)$ \\
$\quad$ Protein & \\
Carbohydrate & 34,573 \\
$\quad$ Water & 402 \\
$B$-factors & 0 \\
Protein & \\
Carbohydrate & \\
r.m.s. deviations & \\
Bond lengths $(\AA)$ & 123.7 \\
Bond angles $\left({ }^{\circ}\right)$ & \\
\hline A & \\
& \\
& \\
&
\end{tabular}

A single crystal was used for both structure determination at 3.2- $\AA$ resolution and refinement. *Values in parentheses are for highest-resolution shell. 
buffer at the Stanford Synchrotron Radiation Laboratory beamline 9.2, set at a wavelength of $1.0 \AA$ and processed with $\mathrm{XDS}^{52}$ and HKL2000 (ref. 53). The structure was solved at $3.2-\AA$ resolution by molecular replacement with PHASER using the structures of H5 (A/Vietnam/1194/04; PDB 2IBX) and a homology model of F10 based on the structure of SARS nAb 80R (PDB $2 \mathrm{GHW})^{54,55}$ as starting models. The asymmetric unit contains two H5 trimers and three F10 molecules per trimer and was refined using REFMAC5 (ref. 56) with simulated annealing in CNS and manual rebuilding with $\operatorname{Coot}^{57}$ and $\mathrm{Xtalview}^{58}$. The final maps are of high quality, and key features such as the F10 CDR loops and interfacial residues are unambiguous and consistent in the six copies. The final model includes 503, 503, 503, 497, 497 and 497 residues for the six independent copies of H5; 235, 235, 236, 233, 234 and 234 residues for the six F10scFvs; $24 \mathrm{~N}$-acetyl-D-glucosamine and six $\beta$-D-mannose units, but no water molecules. The $R_{\text {free }}$ is 0.29 with excellent geometry as assessed with PROCHECK ${ }^{59}$ and Rampage (Table 1): residues in the favored, allowed and outlier regions are $90.0 \%, 9.5 \%$ and $0.5 \%$, respectively.

Phage-display library selection. We produced recombinant trimeric H5-VN04 ectodomain as for crystallization studies except that we did not use furin co-infection to ensure complete activation. Antibodies were identified by two rounds of selection of a 27 billion-membered human scFv phagedisplay library against recombinant trimeric $\mathrm{H} 5$ immobilized on Immunotube (Nunc), followed by ELISA screening. We identified ten unique antiH5 antibodies by sequence analysis of 97 H5-positive clones out of 392 clones screened.

Plaque reduction assay. H5-VN04, H5-IN05 or A/Netherland/219/03 (H7N7) (H7-NL03) viruses (10,000 plaque forming units (p.f.u.)) were incubated with anti-H5 scFv-Fcs at three different concentrations $\left(1 \mu \mathrm{g} \mathrm{ml}^{-1}, 10 \mu \mathrm{g} \mathrm{ml}^{-1}\right.$ or $100 \mu \mathrm{g} \mathrm{ml}^{-1}$ ) at $37{ }^{\circ} \mathrm{C}$ for $30 \mathrm{~min}$. We diluted the virus-antibody mixture logarithmically and transferred the dilutions onto MDCK cell monolayers in 12-well plates, which we then incubated at $37{ }^{\circ} \mathrm{C}$ for $1 \mathrm{~h}$. The cells were then washed and overlaid with agar. After $4 \mathrm{~d}$ of incubation, we discarded the overlay and the plaques were visualized by crystal violet staining.

Microneutralization assay. We carried out the assay as described ${ }^{60}$. Briefly, we mixed $100 \mathrm{TCID}_{50}$ (median tissue culture infectious doses) of virus in equal volume with two-fold serial dilutions of antibody stock solution $\left(0.1 \mathrm{mg} \mathrm{ml}^{-1}\right)$ in 96-well plates and incubated them for $1 \mathrm{~h}$ at $37^{\circ} \mathrm{C}$. Indicator MDCK cells $\left(1.5 \times 10^{4}\right.$ cells per well $)$ were added to the plates, followed by incubation at $37{ }^{\circ} \mathrm{C}$ for $20 \mathrm{~h}$. To establish the endpoint, we washed the cell monolayers with PBS, fixed the cells in acetone and detected viral antigen by indirect ELISA with a mAb against influenza A NP (A-3, Accurate).

Viral binding inhibition assay. We incubated $0.5 \times 10^{6} 293 \mathrm{~T}$ cells with H5-TH04-pseudotyped HIV viruses ( $500 \mathrm{ng}$ of p24) in the presence of antiH5 nAbs or control mAbs, or in the absence of antibodies, in PBS buffer containing $0.5 \%(\mathrm{w} / \mathrm{v}) \mathrm{BSA}$ and $0.02 \%(\mathrm{w} / \mathrm{v}) \mathrm{NaN}_{3}$ at $4{ }^{\circ} \mathrm{C}$. After $1 \mathrm{~h}$ of incubation, cells were spun down, and the supernatants were tested for p24 levels using an HIV-1 p24 ${ }^{\mathrm{CA}}$ capture ELISA kit (National Cancer Institute, US National Institutes of Health) to quantify unbound virus. Cells were then washed once or twice and lysed to quantify the cell-bound virus using the same method.

Cell fusion inhibition assay. We transfected HeLa cells, 90\% confluent in six-well plates, with pcDNA3.1-H5-TH04 plasmid ( $3 \mu \mathrm{g}$ total DNA per well) using lipofectamine 2000 (Invitrogen). After $\sim 30 \mathrm{~h}$ of transfection, the culture medium was supplemented with $1 \mathrm{ml}$ of anti-H5 or control mAbs for 1-2 h, and cells were then washed and incubated with low-pH fusion buffer $(150 \mathrm{mM}$ $\mathrm{NaCl}$ plus $10 \mathrm{mM}$ HEPES, adjusted to $\mathrm{pH} 5.0$ ) for $4-5 \mathrm{~min}$. Cells were then returned to the standard culture medium for $2-3 \mathrm{~h}$ at $37{ }^{\circ} \mathrm{C}$, and finally fixed with $0.25 \%(\mathrm{v} / \mathrm{v})$ glutaraldehyde and stained with $0.1 \%(\mathrm{w} / \mathrm{v})$ crystal violet. Photomicrographs were taken at $10 \times$ magnification.

Prophylactic and therapeutic efficacy studies in mice. We used female 8-10 weeks old $\mathrm{BALB} / \mathrm{c}$ mice in all experiments. Mice were weighed on the day of virus challenge and then daily for 2 weeks. We used body weight as the clinical endpoint; mice with body weight loss $\geq 25 \%$ of pre-infection values were euthanized. Animal studies were conducted as per the approved Institutional Animal Care and Use Committee protocols.

For the prophylactic efficacy study, three human nAbs (D8-IgG1, F10-IgG1 and A66-IgG1) or control human mAb 80R-IgG1 (ref. 18) at $2.5 \mathrm{mg} \mathrm{kg}^{-1}$ or $10 \mathrm{mg} \mathrm{kg}-1$ were administered into four groups of five mice each by intraperitoneal injection in a $0.5 \mathrm{ml}$ volume. At $1 \mathrm{~h}$ after $\mathrm{mAb}$ administration, two groups of mice were challenged with $\mathrm{H} 5-\mathrm{VN} 04$ and two groups with H5HK97 intranasal inoculation with $10 \mathrm{MLD}_{50}$ in $50 \mu \mathrm{l}$ volumes per mouse. Mice were observed and weighed daily for 2 weeks after infection. Analogous studies were performed to evaluate the protective efficacy of the nAbs against A/Puerto Rico/8/1934 (H1N1) or A/WSN/1933 (H1N1) viruses.

For the post-exposure therapy efficacy study, the experimental design recapitulates the prophylaxis study, with the following exceptions. We first inoculated 12 groups of ten mice intranasally with $10 \mathrm{MLD}_{50}$ of VN04. At $24 \mathrm{~h}, 48 \mathrm{~h}$ and $72 \mathrm{~h}$ after H5-VN04 infection, the mice received intraperitoneal injections of $15 \mathrm{mg} \mathrm{kg}{ }^{-1}$ body weight of one of the nAbs or control (80R).

Accession codes. Protein Data Bank: Coordinates and structure factors for the H5-F10 complex have been deposited with accession code 3FKU.

Note: Supplementary information is available on the Nature Structural \& Molecular Biology website.

\section{ACKNOWLEDGMENTS}

We thank J. Appleton (Cornell University) for the gift of mouse mAbs against H5N1, 17A2.1.2 and 22F; A. Klimov (CDC) and A. Balish (CDC) for providing ferret antiserum and virus sequences; R. Webster (St. Jude Children's Research Hospital) for H11N9, H13N6 and H16N3; L. Quynh Mai (National Institute of Hygiene and Epidemiology, Vietnam Ministry of Health) for H5N1; W. Lim (Hong Kong Department of Health) for H5N1 and H9N2, as well as E. Sedyaningsih, T. Soendoro (National Institute of Health Research and Development, Indonesian Ministry of Health) for H5N1 specimens; P. Palese (Mount Sinai School of Medicine) for pCAGGS-H1(SC) plasmid encoding the full-length hemagglutinin protein of H1-SC1918; M. Farzan (New England Primate Research Center, Harvard Medical School) for pCAGGS-H1 (PR) plasmid encoding the hemagglutinin protein of H1-PR34 and X. Yang (Beth Israel Deaconess Medical Center, Harvard Medical School) for pCAGGS-H7 (FPV) encoding H7-FP34 hemagglutinin; and R. Fuller (University of Michigan) for furin cDNA. We thank W. Yuan and W. Li for helpful discussions and Y. Lin for assistance in crystallization and critical discussion. We thank the US National Institutes of Health (NIH) and the Department of Energy (DOE) for access to the Stanford Synchrotron Radiation Facility and the facility staff for assistance in X-ray data collection. Molecular graphics images were produced using the UCSF Chimera package from the Resource for Biocomputing, Visualization, and Informatics at the University of California, San Francisco (supported by NIH P41 RR-01081). This work was supported by NIH (U01-AI074518-01) to W.A.M. and in part by NIH (P01-AI055789) to R.C.L.

\section{AUTHOR CONTRIBUTIONS}

In the DFCI team, J.S. and A.M. constructed H5-TH04 hemagglutinin; J.S. and D.A. performed phage-display antibody library selections and screening for antibodies by ELISA, FACS and pseudovirus-neutralization assays; J.S., M.A. and T.H. carried out epitope mapping using mutagenesis and FACS analysis; J.S., D.A. and M.A. purified antibodies; J.S. and A.Y. analyzed kinetics of antibody binding with hemagglutinin protein; J.S. performed hemagglutinin subtype cross-binding and neutralization assays, pseudovirus binding and fusion inhibition assay; J.S. and W.A.M. designed the study, analyzed data and wrote the sections about these studies. In the BIMR team, R.C.L. supervised all of the work; G.W. and G.C. cloned and expressed recombinant $\mathrm{H} 5$ for antibody panning and crystallization. W.C.H. expressed F10 scFv and crystallized the F10-HA0 complex; W.C.H., E.S. and B.S. collected diffraction data and solved and refined the structure; L.A.B. supervised cloning and expression; W.C.H., L.A.B. and R.C.L. wrote sections about these studies. In the CDC team, S.P., L.C., H.W., N.J.C. and R.O.D. designed the study and performed animal studies as well as virology studies with wild-type viruses; R.O.D wrote sections of these studies; J.S., R.O.D., R.C.L. and W.A.M. finalized the paper. All authors commented on the manuscript. The findings and conclusions in this report are those of the authors and do not necessarily represent the views of the Centers for Disease Control and Prevention or the Agency for Toxic Substances and Disease Registry. 
Published online at http://www.nature.com/nsmb/

Reprints and permissions information is available online at http://npg.nature.com/ reprintsandpermissions/

1. WHO. Factsheet 211: influenza. World Health Organization 〈http://www.who.int/ mediacentre/factsheets/2003/fs211/en/> (2003).

2. Webster, R.G. 1918 Spanish influenza: the secrets remain elusive. Proc. Natl. Acad. Sci. USA 96, 1164-1166 (1999).

3. de Wit, E. \& Fouchier, R.A. Emerging influenza. J. Clin. Virol. 41, 1-6 (2008).

4. WHO. Global influenza surveillance. World Health Organization 〈http://www.who.int/ csr/disease/influenza/influenzanetwork/en/index.html > (2008)

5. Carrat, F. \& Flahault, A. Influenza vaccine: the challenge of antigenic drift. Vaccine $\mathbf{2 5}$, 6852-6862 (2007)

6. Cinatl, J. Jr, Michaelis, M. \& Doerr, H.W. The threat of avian influenza A (H5N1). Part IV: development of vaccines. Med. Microbiol. Immunol. 196, 213-225 (2007).

7. Subbarao, K. \& Luke, C. H5N1 viruses and vaccines. PLoS Pathog. 3, e40 (2007).

8. Leroux-Roels, I. et al. Broad clade 2 cross-reactive immunity induced by an adjuvanted clade 1 rH5N1 pandemic influenza vaccine. PLoS ONE 3, e1665 (2008).

9. Baras, B. et al. Cross-Protection against lethal H5N1 challenge in ferrets with an adjuvanted pandemic influenza vaccine. PLoS ONE 3, e1401 (2008).

10. de Jong, M.D. et al. Oseltamivir resistance during treatment of influenza A (H5N1) infection. N. Engl. J. Med. 353, 2667-2672 (2005)

11. WHO. Clinical management of human infection with avian influenza A (H5N1) virus. World Health Organization 〈http://www.who.int/csr/disease/avian_influenzal guidelines/Clinical Management07.pdf $>$ (2007).

12. Wright, P., Neumann, G. \& Kawaoka, Y. Orthomyxoviruses. in Fields Virology Vol. 2 (eds. Knipe, D., Howley, P., Griffin, D., Lamb, R. \& Martin, M.) 1692-1740 (Lippincott Williams \& Wilkins, Philadelphia, PA, 2006).

13. Fauci, A.S. Pandemic influenza threat and preparedness. Emerg. Infect. Dis. 12, 73-77 (2006)

14. Marasco, W.A. \& Sui, J. The growth and potential of human antiviral monoclonal antibody therapeutics. Nat. Biotechnol. 25, 1421-1434 (2007).

15. WHO. Antigenic and genetic characteristics of $\mathrm{H} 5 \mathrm{~N} 1$ viruses and candidate $\mathrm{H} 5 \mathrm{~N} 1$ vaccine viruses developed for potential use as pre-pandemic vaccines. World Health Organization 〈http://www.who.int/csr/disease/avian_influenza/guidelines/summary H520070403.pdf > (2007)

16. World Health Organization Global Influenza Program Surveillance Network. Evolution of H5N1 avian influenza viruses in Asia. Emerg. Infect. Dis. 11, 1515-1521 (2005).

17. Stevens, J. et al. Structure and receptor specificity of the hemagglutinin from an H5N1 influenza virus. Science 312, 404-410 (2006)

18. Sui, J. et al. Potent neutralization of severe acute respiratory syndrome (SARS) coronavirus by a human $\mathrm{mAb}$ to $\mathrm{S} 1$ protein that blocks receptor association. Proc. Natl. Acad. Sci. USA 101, 2536-2541 (2004).

19. Skehel, J.J. \& Wiley, D.C. Receptor binding and membrane fusion in virus entry: the influenza hemagglutinin. Annu. Rev. Biochem. 69, 531-569 (2000).

20. Kida, H., Yoden, S., Kuwabara, M. \& Yanagawa, R. Interference with a conformational change in the haemagglutinin molecule of influenza virus by antibodies as a possible neutralization mechanism. Vaccine 3, 219-222 (1985).

21. Ha, Y., Stevens, D.J., Skehel, J.J. \& Wiley, D.C. H5 avian and H9 swine influenza virus haemagglutinin structures: possible origin of influenza subtypes. EMBO J. 21, 865-875 (2002).

22. Chothia, C. et al. Structural repertoire of the human VH segments. J. Mol. Biol. 227, 799-817 (1992)

23. Samanta, U., Pal, D. \& Chakrabarti, P. Packing of aromatic rings against tryptophan residues in proteins. Acta Crystallogr. D Biol. Crystallogr. 55, 1421-1427 (1999).

24. Weis, W.I., Brunger, A.T., Skehel, J.J. \& Wiley, D.C. Refinement of the influenza virus hemagglutinin by simulated annealing. J. Mol. Biol. 212, 737-761 (1990).

25. Pal, D. \& Chakrabarti, P. Non-hydrogen bond interactions involving the methionine sulfur atom. J. Biomol. Struct. Dyn. 19, 115-128 (2001).

26. Champ, P.C. \& Camacho, C.J. FastContact: a free energy scoring tool for protein-protein complex structures. Nucleic Acids Res. 35, W556-W560 (2007).

27. Stevens, J. et al. Structure of the uncleaved human $\mathrm{H} 1$ hemagglutinin from the extinct 1918 influenza virus. Science 303, 1866-1870 (2004).

28. Daniels, R.S. et al. Fusion mutants of the influenza virus hemagglutinin glycoprotein. Cell 40, 431-439 (1985)

29. Thoennes, S. et al. Analysis of residues near the fusion peptide in the influenza hemagglutinin structure for roles in triggering membrane fusion. Virology 370, 403-414 (2008)

30. Earp, L.J., Delos, S.E., Park, H.E. \& White, J.M. The many mechanisms of viral membrane fusion proteins. Curr. Top. Microbiol. Immunol. 285, 25-66 (2005).

31. Barbey-Martin, C. et al. An antibody that prevents the hemagglutinin low $\mathrm{pH}$ fusogenic transition. Virology 294, 70-74 (2002)

32. Russell, R.J. et al. $\mathrm{H1}$ and $\mathrm{H7}$ influenza haemagglutinin structures extend a structural classification of haemagglutinin subtypes. Virology 325, 287-296 (2004).
33. Fouchier, R.A. et al. Characterization of a novel influenza A virus hemagglutinin subtype (H16) obtained from black-headed gulls. J. Virol. 79, 2814-2822 (2005).

34. Gamblin, S.J. et al. The structure and receptor binding properties of the 1918 influenza hemagglutinin. Science 303, 1838-1842 (2004).

35. Yamada, S. et al. Haemagglutinin mutations responsible for the binding of H5N1 influenza A viruses to human-type receptors. Nature 444, 378-382 (2006).

36. Ha, Y., Stevens, D.J., Skehel, J.J. \& Wiley, D.C. X-ray structure of the hemagglutinin of a potential H3 avian progenitor of the 1968 Hong Kong pandemic influenza virus. Virology 309, 209-218 (2003).

37. Chen, J., Skehel, J.J. \& Wiley, D.C. N- and C-terminal residues combine in the fusion$\mathrm{pH}$ influenza hemagglutinin $\mathrm{HA}_{2}$ subunit to form an $\mathrm{N}$ cap that terminates the triplestranded coiled coil. Proc. Natl. Acad. Sci. USA 96, 8967-8972 (1999).

38. Sui, J. et al. Broadening of neutralization activity to directly block a dominant antibody-driven SARS-coronavirus evolution pathway. PLoS Pathog. 4, e1000197 (2008).

39. Okuno, Y., Isegawa, Y., Sasao, F. \& Ueda, S. A common neutralizing epitope conserved between the hemagglutinins of influenza $\mathrm{A}$ virus $\mathrm{H} 1$ and $\mathrm{H} 2$ strains. J. Virol. 67, 2552-2558 (1993).

40. Smirnov, Y.A. et al. An epitope shared by the hemagglutinins of $\mathrm{H} 1, \mathrm{H} 2, \mathrm{H} 5$, and $\mathrm{H} 6$ subtypes of influenza A virus. Acta Virol. 43, 237-244 (1999).

41. Smirnov, Y.A., Lipatov, A.S., Gitelman, A.K., Claas, E.C.\& Osterhaus, A.D. Prevention and treatment of bronchopneumonia in mice caused by mouse-adapted variant of avian H5N2 influenza A virus using monoclonal antibody against conserved epitope in the HA stem region. Arch. Virol. 145, 1733-1741 (2000).

42. Lim, A.P. et al. Neutralizing human monoclonal antibody against H5N1 influenza HA selected from a Fab-phage display library. Virol. J. 5, 130 (2008).

43. Huang, C.C. et al. Structural basis of tyrosine sulfation and $\mathrm{VH}$-gene usage in antibodies that recognize the HIV type 1 coreceptor-binding site on gp120. Proc. Natl. Acad. Sci. USA 101, 2706-2711 (2004).

44. Luftig, M.A. et al. Structural basis for HIV-1 neutralization by a gp41 fusion intermediate-directed antibody. Nat. Struct. Mol. Biol. 13, 740-747 (2006).

45. Chan, C.H., Hadlock, K.G., Foung, S.K. \& Levy, S. $V_{H} 1-69$ gene is preferentially used by hepatitis $C$ virus-associated $B$ cell lymphomas and by normal $B$ cells responding to the E2 viral antigen. Blood 97, 1023-1026 (2001).

46. Lee, J.E. et al. Structure of the Ebola virus glycoprotein bound to an antibody from a human survivor. Nature 454, 177-182 (2008)

47. Kashyap, A.K. et al. Combinatorial antibody libraries from survivors of the Turkish H5N1 avian influenza outbreak reveal virus neutralization strategies. Proc. Natl. Acad. Sci. USA 105, 5986-5991 (2008)

48. Scherer, E.M., Zwick, M.B., Teyton, L. \& Burton, D.R. Difficulties in eliciting broadly neutralizing anti-HIV antibodies are not explained by cardiolipin autoreactivity. AIDS 21, 2131-2139 (2007).

49. Selvarajah, S. et al. Focused dampening of antibody response to the immunodominant variable loops by engineered soluble gp140. AIDS Res. Hum. Retroviruses 24 301-314 (2008)

50. Scheerlinck, J.P. et al. Redistribution of a murine humoral immune response following removal of an immunodominant $\mathrm{B}$ cell epitope from a recombinant fusion protein. Mol. Immunol. 30, 733-739 (1993).

51. Throsby, M. et al. Heterosubtypic neutralizing monoclonal antibodies cross-protective against $\mathrm{H} 5 \mathrm{~N} 1$ and $\mathrm{H} 1 \mathrm{~N} 1$ recovered from human $\operatorname{lgM}^{+}$memory $\mathrm{B}$ cells. PLOS ONE 3 e3942 (2008).

52. Kabsch, W. Automatic processing of rotation diffraction data from crystals of initially unknown symmetry and cell constants. J. Appl. Cryst. 26, 795-800 (1993).

53. Otwinowski, Z.O. \& Minor, W. Processing of X-ray diffraction data collected in oscillation mode. Methods Enzymol. 276, 307-326 (1997).

54. Hwang, W.C. et al. Structural basis of neutralization by a human anti-severe acute respiratory syndrome spike protein antibody, 80R. J. Biol. Chem. 281, 34610-34616 (2006).

55. Rodriguez, R., Chinea, G., Lopez, N., Pons, T. \& Vriend, G. Homology modeling, mode and software evaluation: three related resources. Bioinformatics 14, 523-528 (1998).

56. Murshudov, G.N., Vagin, A.A. \& Dodson, E.J. Refinement of macromolecular structures by the maximum-likelihood method. Acta Crystallogr. D Biol. Crystallogr. 53, 240-255 (1997).

57. Emsley, P. \& Cowtan, K. Coot: model-building tools for molecular graphics. Acta Crystallogr. D Biol. Crystallogr. 60, 2126-2132 (2004).

58. McRee, D.E. A visual protein crystallographic software system for X11/Xview. J. Mol. Graph. 10, 44-46 (1992).

59. Laskowski, R.A., MacArthur, M.W., Moss, D.S. \& Thornton, J.M. PROCHECK: a program to check the stereochemical quality of protein structures. J. Appl. Cryst. 26, 283-291 (1993).

60. Rowe, T. et al. Detection of antibody to avian influenza A (H5N1) virus in human serum by using a combination of serologic assays. J. Clin. Microbiol. 37, 937-943 (1999).

61. Bullough, P.A., Hughson, F.M., Skehel, J.J. \& Wiley, D.C. Structure of influenza haemagglutinin at the $\mathrm{pH}$ of membrane fusion. Nature 371, 37-43 (1994) 